\title{
Legal Determinants of Health: Regulating Abortion Care
}

Pre-publication version: published version in Public Health Ethics (2020) 13(1):3440 at doi:10.1093/phe/phaa014

Sheelagh McGuinness*, University of Bristol Law School Jonathan Montgomery, University College London

*Corresponding author: Sheelagh McGuinness, Reader in Law, Centre for Health, Law, and Society, University of Bristol Law School, Rm 2.03, 8-10 Berkeley

Square, Bristol BS8 1HH, UK. Tel.: p44 (0) 11739 40094; Email: sheelagh.mcguinness@bristol.ac.uk

\section{Section 1: Introduction}

In The legal determinants of health: Harnessing the power of law for global health and sustainable development Gostin et al provide a sustained account of how law can and should be used as an instrument of health promotion (Gostin et al, 2019). We pick up on the themes of this report with a specific focus on the importance of abortion for women's sexual and reproductive health and the impact that particular ways of framing abortion in law can have on the lives of women and girls. In this short comment we wish to emphasise that abortion regulations need to move beyond traditional frameworks based on understandings of harm towards more progressive agendas that take into account the social determinants of health in order to reduce barriers to care. This contribution is particularly relevant to the Commission's criticism that those "[I]aws that stigmatise or discriminate against marginalized populations are especially harmful and exacerbate health disparities" (Gostin et al, 2019) of which they note restricting reproductive rights is a common example.

In this contribution we follow the approach recommended by Hawkes and Buse which problematizes the ways in which public and global health institutions perpetuate problematic gender norms by focusing on the role of women as 'reproducers' (Hawkes and Buse, this issue). We advocate for a conceptualization of access to abortion that moves beyond consideration of abortion merely as an aspect of reproductive function and instead argue it is necessary for the realization of rights in all spheres. The key concern is how to ensure access to and the safety of a common medical procedure. It is estimated that over 25 million unsafe abortions were experienced by women between 2010-2014, due either to unqualified personnel or unsafe methods, almost all in developing countries (Ganatra et al, 2017). It is thought that 193,000 women died as a result of unsafe abortions between 2003-2009 (Day et al, 2014). This presents a major public health challenge. It should be an open question the extent to which, if at all, abortion care must be subject to specific regulation and law should not be used to coerce women into 
engaging with medical services unnecessarily (Erdman, Jelinska \& Yanow, 2018). In this contribution we adopt a reproductive justice approach to understanding access to abortion. Such an approach is attendant to the wide-ranging cultural, social, and political barriers which woman can face in accessing abortion care and realizing their rights to bodily integrity (Ross, 2006). Such an approach is therefore similar to those definitions of public health which acknowledge the important role for social coordination in ensuring optimum conditions for health with justice across the population (Verweij and Dawson, 2009; Coggon, 2012: Part I)

Our analysis vindicates the claim that law plays a significant role in determining health. However, as Gostin et al note 'law can also be a formidable barrier to achieving global health and equity' (Gostin et al, 2019). We suggest that there is a normative content to the rule of law that draws attention to the injustices that women experience in abortion care. Greater attention to these aspects of the legal determinants of health will enhance the prospects of harnessing the power of law to achieve sustainable global health with justice.

\section{Section 2: Law as a weapon}

Abortion seems to offer a counter-example to the thesis that law can translate vision into action because abortion law has often been a battleground in culture wars that have prevented a consensus on the human rights dimensions settling and obscured health issues (Zampas and Gher, 2008). In Europe both the drafting and litigation processes have failed to resolve the question of whether human foetuses and embryos are rights-holders, ${ }^{1}$ although the Parliamentary Assembly of the Council of Europe has called for the decriminalisation of abortion and called on its member states to 'guarantee women's effective exercise of their right of access to a safe and legal abortion'. ${ }^{2}$ Only the African Charter explicitly recognises that authorisation of abortion is required by women's reproductive rights although this is limited to reducing certain types of harms - 'where the continued pregnancy endangers the mental and physical health of the mother or the life of the mother' ${ }^{3} A$ narrow focus on limitation of specific sorts of physical or mental harm doesn't take into account the broader nature of harms that lack of access to abortion may give rise to. Nor does it consider the extent to which regulation itself may harm women, including in social and economic harms. As Charles Ngwena cautions: "The health care sector mirrors society in its propensity to violate women's reproductive rights through systemically embedded laws, policies, practices and values that draw from harmful stereotypes" (Ngwena, 2016).

In terms of global health governance, like the UNESCO Declaration on Bioethics, Sustainable Development Goal 7.3 is silent on abortion. In 'World Health Statistics 2019: Monitoring Health for the SDGs', the monitoring report, discussion of abortion

\footnotetext{
${ }^{1}$ Vo v France [2004] ECHR 326

2 'Access to safe and legal abortion in Europe' Resolution 1607 (2008), Access to safe and legal abortion in Europe, Art 7.2.

${ }^{3}$ Protocol on the Rights of Women in Africa, Art 14.
} 
is limited to a consideration of sex selection. ${ }^{4}$ The Cairo Programme of Action in 1994 specifically acknowledged the importance of women being able to control the timing and number of their children and produced a 20-year roadmap to achieve this and other goals. Cairo was the first occasion when improving the safety of abortion provision was identified as a key public health tool for reducing maternal morbidity and mortality (Hessini, 2005). However, as noted by Erdman, the general support for controlling the timing and number of children outlined in Cairo was circumscribed by stating that control of reproduction must be by lawful means (Erdman, 2016). She summarises this as follows:

Governments agreed to address the devastating public health impacts of unsafe abortion as a human rights concern, but to otherwise leave abortion to the democratic forces of the nation-state. (p.40)

She further highlights the fact that Cairo was concerned with reducing certain sorts of harms which lack of access would give rise to and as such fails in setting an agenda for a more progressive realisation of rights and empowerment.

The picture in relation to constitutional rights is mixed (see for example deLondras, 2015). In the USA, despite the Supreme Court's ruling that foetuses do not hold constitutional rights, ${ }^{5}$ campaigners have refused to accept this position. In Canada, a Supreme Court ruling that the criminalisation of abortion was unconstitutional has led to regulation as a health procedure and attempts to recriminalize have failed (Erdman, 2017). Notwithstanding this questions of access remain. ${ }^{6}$ In Ireland the constitutional status of the fetus has changed twice as a result of plebiscites (deLondras, 2015; deLondras and Enright, 2018). In a review of Ugandan law on abortion Charles Ngwena has highlighted the legacy of historic criminalization of abortion care and the continuing problems of lack of full implementation of constitutional protections in this area (Ngwena, 2016). He states that this "accentuates the stigmatization of abortion through a double discourse in which laws that permit abortion are juxtaposed with state practices that deny abortion". As such the battle over abortion rights has failed to address issues that face women, and in that sense can be as much barrier rather than a benefit. As the Lancet O'Neill Commission explicitly note:

[L]aw can also be a formidable barrier to achieving global health and equity. Throughout history, misguided, out-dated, arbitrary, or discriminatory laws have caused great harm. Punitive laws, for example, can discourage marginalised individuals from accessing care, restrict reproductive rights, and enable discrimination in employment or insurance. (Gostin et al, 2019)

Arguably, this is a product of abortion exceptionalism (Corbin, 2014) and should not lead to the conclusion that law cannot be a determinant of health so much as its limitation in the face of conflicting political pressures. Abortion therefore occupies

\footnotetext{
4 'World Health Statistics 2019: Monitoring health for the SDGs' https://www.who.int/gho/publications/world_health_statistics/2019/en/

${ }^{5}$ Roe v. Wade, 410 U.S. 113 (1973)

6 'Unequal Access to Abortion Across Canada' (Action Canada for Sexual Health and Rights, 2019)
} 
an interesting place in a medico-legal context. Public health framings may inadvertently stigamtise abortion by emphasising it as dangerous or something that necessitates medical control. However, advances in abortion technologies mean that this is no longer always the case. Medical oversight may be absolutely vital for some women but for others less so and access to care needs to recognise the range of barriers that women may face and design appropriate care pathways and interventions (see in particular Erdman, Jelinska \& Yanow, 2018).

\section{Section 3: Good governance and access to safe abortion globally}

Abortion is the most common surgical procedure that women will undergo, with approximately one third of women experiencing it by the age of 45 . When provided by appropriately trained individuals, or accessed with appropriate supports, abortion can be safe in a range of contexts. Indeed the WHO states that when performed appropriately it is safer than the continuance of pregnancy. ${ }^{78}$ However, we must be cautious about overly binary framings of abortion in global health governance. As Erdman (2016) as observed

Within the pragmatic discourse of global abortion rights, unsafe abortion is a public health problem, and its solution resides in the tools of this field: provision of information and services, training of providers, and equipping of facilities-a technical set of interventions with decriminalization in the mix. Consider the World Health Organization's Safe Abortion: Technical and Policy Guidance for Health Systems, which offers clinical, service delivery, and policy recommendations all in one document. The guidance subjects criminal law to the same evidence-based standards as clinical medicine and service delivery design. The measure of the law's legitimacy is its health impact, to which the authority of international human rights law is then attached. In this global discourse, political conflicts over abortion law are not so much denied as suggested to be almost beside the point, a mischaracterization of the issue. (page 50)

Globally a theme that links many of the legal frameworks that limit access to abortion is that they are framed within moral or criminal codes rather than being directed towards the vindication of rights. As Erdman cautions above the measure of whether legal restrictions are warranted are the extent to which they impact health outcomes. However, these tend to be limited in the narrowest of understandings of health rather than wider understandings that pay attention to broader issues of physical and social well-being, including any gendered harms perpetuated by continued 'over regulation'. ${ }^{9}$ Yet, as noted by Gostin et al, laws that criminalise abortion do not reduce the number of abortions taking place; abortions take place at roughly the same rates in countries where abortion is prohibited as in countries

\footnotetext{
${ }^{7}$ Safe Abortion: Technical and Policy Guidance for Health Systems ( $2^{\text {nd }}$ Edition) (World Health Organisation, 2012)

http://www.who.int/reproductivehealth/publications/unsafe_abortion/9789241548434/en/

${ }^{8}$ Leading Safe Choices (RCOG, 2016) https://www.rcog.org.uk/en/global-network/global-healthprojects-and-partnerships/leading-safe-choices/

${ }^{9}$ Global Abortion Policies Database https://abortion-policies.srhr.org/
} 
where it is allowed. ${ }^{10}$ However, criminalization does impact the safety of abortion with evidence of links between increased incidences of criminalization with increased rates of maternal morbidity and mortality (Sedgh, 2016). As such decriminalization is a primary strategy in global abortion advocacy. However, we also need to consider what happens after decriminalization and how health law institutions can translate vision into action with regard to access to abortion and address a wide range of barriers to care.

To summarise abortion laws evidence why we should be cautious about the claim that law is necessarily, or even generally, a tool for translating the vision for sustainable development goals into action (the first way in which law is seen as a determinant of health). This is because, as Gostin et al emphasise, it is a tool that can 'cut both ways' (Gostin et al, 2019). Nevertheless, there are important features of the 'inner morality' of law that provide constraints against the use of law as a tool of oppression, stigmatization and an adverse determinant of health (Fuller, 1969). When these are properly recognised, then the law operates to support good governance (legal determinant 2) and promote fair treatment (legal determinant 3). The politicization of abortion law has distorts the opportunity for law as a determinant of health. As such the role of law as a determinant of health in relation to safe health services is poorly extended to abortion provision. While Sexual and Reproductive Health advocacy has successfully engaged with human rights frameworks it also clear that law and medicine can be a powerful coalition in the perpetuation of harmful constructions of women in need of abortion care through processes of criminalization, control, and power (Sheldon, 1997).

Hawkes and Buse right in cautioning that although health care systems might be "gender-blind" they "are rarely gender-neutral" (Hawkes and Buse, this issue). In the field of SRHR unnecessary and harmful restrictions on access to healthcare are common and as such health care systems can be complicit in the perpetuation of gendered harms. Restrictions placed on access to abortion include medically unnecessary waiting periods, unnecessary informed consent rules, parental notification requirements, and clinically unnecessary restrictions on where and who can carry out abortions (Culwell and Hurwitz, 2013). Such restrictions serve to obstruct and stigmatise abortion. They are also unequally experienced by women depending on a range of socio-cultural barriers that they face (Sedgh et al 2018).

The decriminalisation of abortion in Northern Ireland has brought the need to reframe the governance challenges and provides an opportunity to imagine abortion regulations that facilitate excellent clinical care in a human rights enhancing and respectful way. In the words of Dame Lesley Regan, former President of the Royal College of Obstetricians and Gynaecologists, "is an opportunity to establish a firstclass abortion care service, where the needs of women and their families are at the centre of the care they receive. And where healthcare professionals can care for women without fear of prosecution". Such regulation would meet the features outlined in the Commission's framework for evaluating evidence based health law. It

10 'The World's Abortion Laws' https://reproductiverights.org/worldabortionlaws\#law-policy-guide 
is to be hoped that the regulations to be produced in Northern Ireland meet this goal. Northern Ireland in moving from being an outlier in terms of infringing human rights in the context of reproduction could potential be a global example of how law can serve, rather than frustrate, challenges for global health and justice. The regulations being drafted could provide an example of law serving rather than frustrating a challenge for global health and justice (see further McGuinness and Montgomery, 2019).

\section{Section 4: Capacity building and the barrier of 'conscientious' resistance}

We suggest that taking seriously the fourth legal determinant in relation to building capacity for health requires challenging claims made by some professionals and organizations about their 'right' of conscientious objection. In other areas of human rights abuses, such as female genital mutilation and cutting, or customary procedures states are obliged to confront customary objections but in the context of abortion many states permit individuals to opt out of meeting health needs through abortion and in some institutions are also allowed to breach human rights in this way. ${ }^{11}$ Discussions of conscientious objection often elevate the status of personal beliefs in professional contexts and over emphasise these claims as an important mechanism for protecting individual integrity and agency. Yet at the same time there is a failure to consider access to abortion as an issue of integrity nor any attempt to 'balance' the competing rights that are at play. It is important to note that invocations of rights to refuse certain sorts of care is highly stigmatizing of that care and also the people who need to access it. The development of universal health coverage should take seriously the possibility that health systems can be used as a mechanism for perpetuating gendered harms. And it should be sensitive to the history of how law and medicine have worked together to discriminate against, and control, women in the sphere of reproduction.

There is a danger in regulations that treat abortion solely as an issue of moral dispute in need of a 'compromise' between competing sides. Cathleen Kaveny, critiquing laws on conscientious objection, makes the following observation of the form of such arguments: "A decent society ought to ban abortions but at the very least, it ought to protect those morally courageous doctors who refuse to perform it" (as cited in NeJaime \& Siegel, 2015). Generally this argument has the form that 'abortion ought to be banned but at the very least it should be highly regulated and restricted'. Laws that attempt to balance competing views about the morality of abortion risk doing so at the risk of undermining clinically appropriate care. Unnecessary barriers, e.g. waiting periods, must be reduced or removed, and if there are protections for clinicians who wish to refuse to provide certain sorts of care then their scope should be carefully qualified (Dickens, 2000; Cook \& Dickens, 2006). This approach to good governance is compliant with human rights requirements that abortion is legally available and also accessible and also that conscientious objection has a much less certain status in international human rights norms. ${ }^{12}$ It also serves the wider demands of sustainable health and global health justice. Access to sexual

\footnotetext{
${ }^{11}$ Convention on the Elimination of All Forms of Discrimination against Women

12 See further Law and Policy Guide: Conscientious Objection (Center for Reproductive Rights, 2019) https://reproductiverights.org/law-and-policy-guide-conscientious-objection
} 
and reproductive health care has obvious health impacts on the lives of women and girls. However, in addition to these health impacts there are wider social and cultural consequences, e.g. ability to access education or enter the workforce (Cook 1993; Bunch 1990). Although just one part of the sexual and reproductive rights (SRHR) landscape, access to safe abortion services is vital to achieving health with justice for women and girls worldwide. As such in the development of universal healthcare coverage it is important that Hawkes and Buse's recommendation be adopted:

Ensuring that laws, policies, plans and programmes for UHC take gender (and other social stratifiers) into account, and do not rest upon the assumption that UHC is likely to be gender-neutral and universal.

To summarise then if we are to take an evidence based approach that aims to promote health with justice one of the clearest harms in this area will be laws which restrict or obstruct access to abortion care. The most obvious mechanism then to reduce maternal morbidity and mortality in this area will be the removal of inappropriately restrictive law and regulation.

\section{Section 5: Conclusion}

In the area of sexual and reproductive health and rights (SRHR) law is a significant determinant of health and as such has important consequences for achieving gender justice. The legal framework has important consequences for how women access abortion and is as likely to give rise to barriers as not. However, it need not be this way. As we outline above laws that have the vindication of the rights of women and girls at their core can promote equality and reduce marginalisation and vulnerability.

Kate Greasley has argued 'regulating abortion is not the same as moralizing about it' (Greasley, 2017). Sally Sheldon suggests that 'abortion services might simply be regulated by the same mass of general criminal, civil, administrative and disciplinary regulations that govern all medical practice (Sheldon, 2016). The first principle of medical ethics translates into a core aim of healthcare regulation that has at its heart patient safety (Quick, 2017). Arguably then the first principle of medical ethics is as pertinent to law as it is to health care practice: legal regulation should not itself be the cause of harm. Yet, legal regulation of abortion has clear potential to have, to use Carol Smart's phrase, 'juridogenic' effect (Smart, 1989). This may be directly, e.g. through criminalisation of services, or indirect, e.g. creating barriers for access to care. However, as Smart notes there is a danger in assuming that the response to this harm is increased use of the same legislative tools.

As outlined in the Lancet O'Neill Commission Report law and legal frameworks in the area of health should be evidence based and promote the wider aims of global health with justice. Regulating abortion in line with evidence that promotes best clinical practice in order to reduce maternal morbidity and mortality, rather than within moral criminal law frameworks, is vital for the vindication of human rights and promotion of health equity both globally and nationally.

\section{References}


Barot, S., (2014) Looking back while moving forward: Marking 20 years since The International Conference on Population and Development. Guttmacher Policy Review 17: 22-28.

Bunch, C., (1990) Women's rights as human rights: Toward a re-vision of human rights. Human Rights Quarterly 12: 486-449.

Coggon, J. What Makes Health Public? (Cambridge University Press, 2012)

Cook, Rebecca J. 1993. Women's International Human Rights Law: The way forward. Human Rights Quarterly 15: 230-261.

Cook, R., and Dickens, B., (2000) The scope and limits of conscientious objection. International Journal of Gynaecology \& Obstetrics. 71(1):71-77.

Cook, R., and Dickens, B., (2006) The Growing Abuse of Conscientious Objection. Virtual Mentor 8(5):337-340.

Corbin, C., (2014) Abortion Distortions. Washington and Lee Law Review 71(2) 11751210

Culwell, K.R., and Hurwitz, M., (2013) Addressing barriers to safe abortion. International journal of gynaecology and obstetrics 121 Suppl 1, S16-9

deLondras, Fiona (2015) Constitutionalizing fetal rights : a salutary tale from Ireland. Michigan Journal of Gender and the Law, 22(2) 243-289.

deLondras, F., and Enright, M., Repealing the $8^{\text {th }}$ : Reforming Irish Abortion Law (Policy Press, 2018)

Erdman, J. N., (2016) The Politics of Global Abortion Rights. Brown Journal of World Affairs 22(2) 39

Erdman, J. N., (2017) Constitutionalizing Abortion Rights in Canada. Ottawa Law Review 49(1) 221-261

Erdman, J.N., Jelinska, K. \& Yanow, S. (2018) Understandings of self-managed abortion as health inequity, harm reduction and social change. Reproductive Health Matters 26:54, 13-19

Fuller, L., The Morality of Law (New Haven, rev. edn. 1969)

Ganatra, B., Gerdts, C., Rossier, C. Ronald Johnson, B., Tunçalp, O. Assifi, A., Sedgh, G., Singh, S., Bankole, A., Popinchalk, A., Bearak, J., Kang, Z., Alkema, L., (2017) Global, regional, and subregional classification of abortions by safety, 2010-14: estimates from a Bayesian hierarchical model. The Lancet, 390(10110): 2372-81. 
Greasley, K., Argument about Abortion: Personhood, Morality and the Law (OUP, 2017)

Hawkes, S. and Buse, K., (2020) Socially Constructed Determinants of Health: The case for synergies to arrive at gendered global health law. Public Health Ethics, (this issue)

Hessini, L., (2005) Global Progress in Abortion Advocacy and Policy: An Assessment of the Decade since ICPD. Reproductive Health Matters, 13:25, 88-100

Gostin, L., Monahan, J., Kaldor, J., Debartolo, M., Friedman, E., Gottschalk, K., Kim SC, Alwan A, Binagwaho A, Burci GL, Cabal L, DeLand K, Evans TG, Goosby E, Hossain S, Koh H, Ooms G, Roses Periago M, Uprimny R, Yamin AE (2019). The legal determinants of health: Harnessing the power of law for global health and sustainable development. The Lancet, 393(10183), 1857-1910.

McGuinness, S., \& Montgomery, J., Abortion Law Reform in Northern Ireland https://legalresearch.blogs.bris.ac.uk/2019/10/abortion-law-reform-in-northernireland/

Nejaime, D., and Siegel, R., (2015) Conscience Wars: Complicity-Based Conscience Claims in Religion and Politics. Yale Law Journal 124, 2516-2591

Ngwena, C., (2016) Taking Women's Rights Seriously: Using Human Rights to Require State Implementation of Domestic Abortion Laws in African Countries with Reference to Uganda Journal of African Law 60(1) 110-140

Quick, O., Regulating Patient Safety: The End of Professional Dominance? (Cambridge University Press, 2017)

Ross, L., 'Understanding Reproductive Justice' (SisterSong Women of Color Reproductive Health Collective, 2006)

https://d3n8a8pro7vhmx.cloudfront.net/rrfp/pages/33/attachments/original/14564 25809/Understanding RJ Sistersong.pdf?1456425809

Say, L., Chou, C., Gemmill, A., Tunçalp, O., Moller, A-B., Daniels, J., Gülmezoglu, A.M., Temmerman, M., Alkema, L., (2014). Global causes of maternal death: a WHO systematic analysis. The Lancet Global Health Jun; 2(6):e323-33.

Sedgh G., et al., (2016) Abortion incidence between 1990 and 2014: global, regional, and subregional levels and trends. The Lancet 388(10041) 258-267

Sedgh, G. et al., 'Abortion Worldwide 2017: Uneven Progress and Unequal Access' (Guttmacher Institute, 2018) https://www.guttmacher.org/sites/default/files/report pdf/abortionworldwide-2017.pdf 
Sheldon, S., (2016) British Abortion Law: Speaking from the Past to Govern the Future Modern Law Review 79(2) 283-316

Sheldon, S. Beyond Control: Medical Power, Women and Abortion Law (Pluto Press, 1997)

Singh, S., (2010) Global consequences of unsafe abortion. Women's Health 6: 849860.

Smart, C., Feminism and the Power of Law. (Routledge, 1989)

Verweij, M. and Dawson, A., 'The Meaning of 'Public' in 'Public Health', in A. Dawson and M. Verweij (Eds) Ethics, Prevention, and Public Health. (Oxford University Press, 2009)

Zampas, C., and Gher, J.M., (2008) 'Abortion as a Human Right - International and regional Standards' Human Rights Law Review, 8(2) 249-294. 